\title{
ANÁLISE DE TRADUÇÃO DE NOMES PRÓPRIOS DE PERSONAGENS DA HISTÓRIA INFANTIL “PEDRO E TINA” PARA LIBRAS
}

Laís dos Santos di Benedetto ${ }^{1}$, Maitha Legiehn Rodrigues ${ }^{1}$, Soraia Machado Tuqui ${ }^{1}$, Neiva de Aquino Albres ${ }^{2}$

${ }^{1}$ Instituto Superior de Educação de São Paulo - Singularidades, Curso de Especialização em Tradução e Interpretação em Libras/Português, São Paulo, SP. ${ }^{2}$ Universidade Federal de Santa Catarina - UFSC, Curso de Letras Libras, Centro de Comunicação e Expressão/CCE, Departamento de Artes e Libras/DALi. E-mail: (libras.lais@hotmail.com).

\section{RESUMO}

Nesse trabalho, foi analisado um trecho da tradução do livro "Pedro e Tina: Uma amizade muito especial". O objetivo deste trabalho foi explorar os aspectos da tradução da literatura infantil, discutindo possíveis dificuldades e soluções tradutórias encontradas, em específico, para a tradução dos nomes próprios dos personagens. Este trabalho tem caráter qualitativo, sendo analítico-descritivo, baseado na teoria de Bahktin e Volochinov (1992), sobre o enunciado discursivo, entre outros autores adeptos dessa corrente. Os resultados mostraram que a escolha tradutória para os personagens se deu pela criação de sinais que foram baseados em dois aspectos, psicológico e físicos dos personagens. Assim sendo, as imagens ilustradas influenciaram nas escolhas dos sinais, pois podiam representar a ideia abstrata da personalidade e do sinal escolhido.

Palavras-chave: tradução, língua de sinais, histórias infantis, surdez.

\section{ANALYSIS TRANSLATION OF NAMES CHARACTERS CHILDREN'S STORY "PEDRO AND TINA" FOR LIBRAS}

\begin{abstract}
In this study, we analyzed a book translation " Pedro and Tina: A very special friendship." The aim of this study was to explore aspects of the translation of children's literature, discussing possible problems and translational solutions found, in particular, to the translation of the names of the characters. This study is qualitative, and analytical -descriptive, based on Bahktin theory and Voloshinov (1992) on the enunciation discursive, among other authors supporters of this current. The results showed that translation choice for the characters given by creating signals that werebased on two aspects of psychological and physical characters. Thus, the illustrated images influenced the choices of the signs because they could represent the abstract idea of the personality and the chosen signal.

Keywords: translation, sign language, children's stories, deafness.
\end{abstract}




\section{INTRODUÇÃO}

$\mathrm{Na}$ construção da tradução de um material para o público infantil, no qual constam diversas expressões na língua portuguesa, se faz necessário escolhas tradutórias na língua de sinais, para que faça sentido ao leitor surdo.

Nesse trabalho, faremos análise de um trecho da tradução do livro "Pedro e Tina: Uma amizade muito especial". Esse livro conta a estória de duas crianças que se conhecem por acaso e, desde então, estão sempre juntas. Elas aprendem, uma com a outra, formas diferentes de enfrentar situações da vida.

A estória apresenta Pedro, um menininho muito atrapalhado, que não consegue ao menos desenhar uma linha reta. E Tina, uma garotinha completamente diferente de Pedro, que faz tudo dentro dos padrões esperados e considerado correto pela maioria da sociedade. O enredo mostra que é possível criar laços de amizade mesmo sendo pessoas diferentes e que há formas diversas de se fazer as coisas.

O objetivo deste trabalho é analisar os aspectos da tradução de um discurso da literatura infantil, discutindo possíveis dificuldades e soluções tradutórias encontradas, em específico, a tradução dos nomes próprios dos personagens, o garoto Pedro e a menina Tina e o porquê de cada sinal-nome escolhido.

Sabe-se que as escolhas tradutórias variam e que, muitas vezes, os tradutores e intérpretes de línguas de sinais optam por traduzir nomes próprios usando soletração (o alfabeto manual) ou convencionando sinais para tais personagens, que foi o caso deste discurso escolhido. Sobral (2012) diz que quando há personagens surdos, há maior interesse deste público. Nesta estória não há personagens surdos, mas o fato dos tradutores darem sinais em língua de sinais para os personagens, já aproxima este público, que no caso tem uma especificidade, é infantil.

A escolha deste trecho para análise, é de fundamental importância e merece atenção, uma vez que o estudo sobre tradução para língua de sinais de literatura infantil ainda se encontra em uma condição carente de pesquisas científicas. E pesquisas sobre nomes próprios de personagens apresenta situação ainda mais tímida, não havendo uma vasta referência a ser consultada. Contudo, há algumas pesquisas que já foram desenvolvidas como a de Karnopp (2010), Quadros e Sutton-Spence (2006), Silveira (2006), Strobel (2008), Wilcox (2005) e Albres (2016).

\section{FUNDAMENTAÇÃO TEÓRICA}

Mourão (2012) enfatiza a importância das pessoas terem acesso à literatura e enfatiza como isso pode influenciar em suas vidas. Tal como os ouvintes, os surdos têm direito à educação e também à cultura, ele salienta:

[...] já se sabe há bastante tempo que a literatura tem poder de influenciar o público que lê, fazendo as pessoas viverem suas histórias e acreditarem nas representações que traz. Mesmo que seja difícil comprovar como os livros produzem opiniões e comportamentos, o fato é que isso acontece com frequência (MOURÃO e SILVEIRA 2009, p. 2 apud Mourão, 2012 p. 4).

Aguilera (2008), ressalta a importância de se traduzir nomes próprios dos personagens e, suprimir isso pode influenciar até mesmo no sentido da história contada. Silva (2009) contribui significativamente para a literatura da área, em que traz ideias de autores como Peter Newmark para a discussão de tradução de nomes de personagens. Outra autora que vem oferecendo importantes pesquisas sobre o tema é Albres, em um de seus trabalhos, mostra a análise de uma tradução infantil e discute a escolha tradutória de nomes próprios, além disso, traz autores como Moreira (2007) que discute ideias sobre os espaços utilizados na tradução, Lacerda (2000) que discute o sentido das enunciações traduzidas, Lidell (2003) que argumenta sobre os espaços mentais e, Bahktin e sua teoria enunciativa/discursiva (ALBRES, 2012). 
Mais especificamente, sobre a tradução de sinal-nome, Albres (2016) indica que há quatro categorias de sinais-nomes em Línguas de Sinais: (1) sinais-nome arbitrários (2) sinais-nome descritivos (3) sinais-nome inicializados e descritivos (híbrido) (4) sinais-nome emprestados.

Ainda sobre Bahktin, outro autor que pretendemos trabalhar será Sobral (2012, p. 125) que diz: "A rigor, não há para Bakhtin uma concepção de sentido como algo destacável do criar sentido, do processo de instauração de sentidos" que vai ao encontro das ideias apresentadas por Lacerda. Esses autores embasaram a análise que será apresentada abaixo, a fim de nos levar a entender tais escolhas realizadas pelos tradutores do livro apresentado acima. Muitos conceitos discutidos por eles serão discorridos e debatidos, após apresentarmos o trecho traduzido.

\section{METODOLOGIA}

Esta pesquisa configura-se como de caráter qualitativo, sendo analítico-descritiva. $O$ objeto escolhido foi a tradução da língua portuguesa para a Libras do livro "Pedro e Tina: Uma amizade muito especial", cujo autor foi Stephen Michael King e traduzida pelos estudantes do último termo da pós-graduação em tradução em Libras/Português da turma 2 do Instituto Singularidades de São Paulo.

A análise foi construída baseada na teoria de Bahktin e Volochinov (1992), sobre o enunciado discursivo. Efetuamos recortes do vídeo traduzido e os apresentamos em forma de glosa, a fim de apresentar os sinais a serem analisados. Conforme apresentado acima, o objetivo deste trabalho é a análise, tendo isso em vista, além da observação dos vídeos, a consulta bibliográfica dos teóricos que tratam do tema em questão, já apresentados acima.

A partir de agora, mostraremos os resultados que serão discutidos a seguir.

\section{RESULTADOS}

Tabela 1. Sequência da sinalização apresentada na tradução (trecho 1)

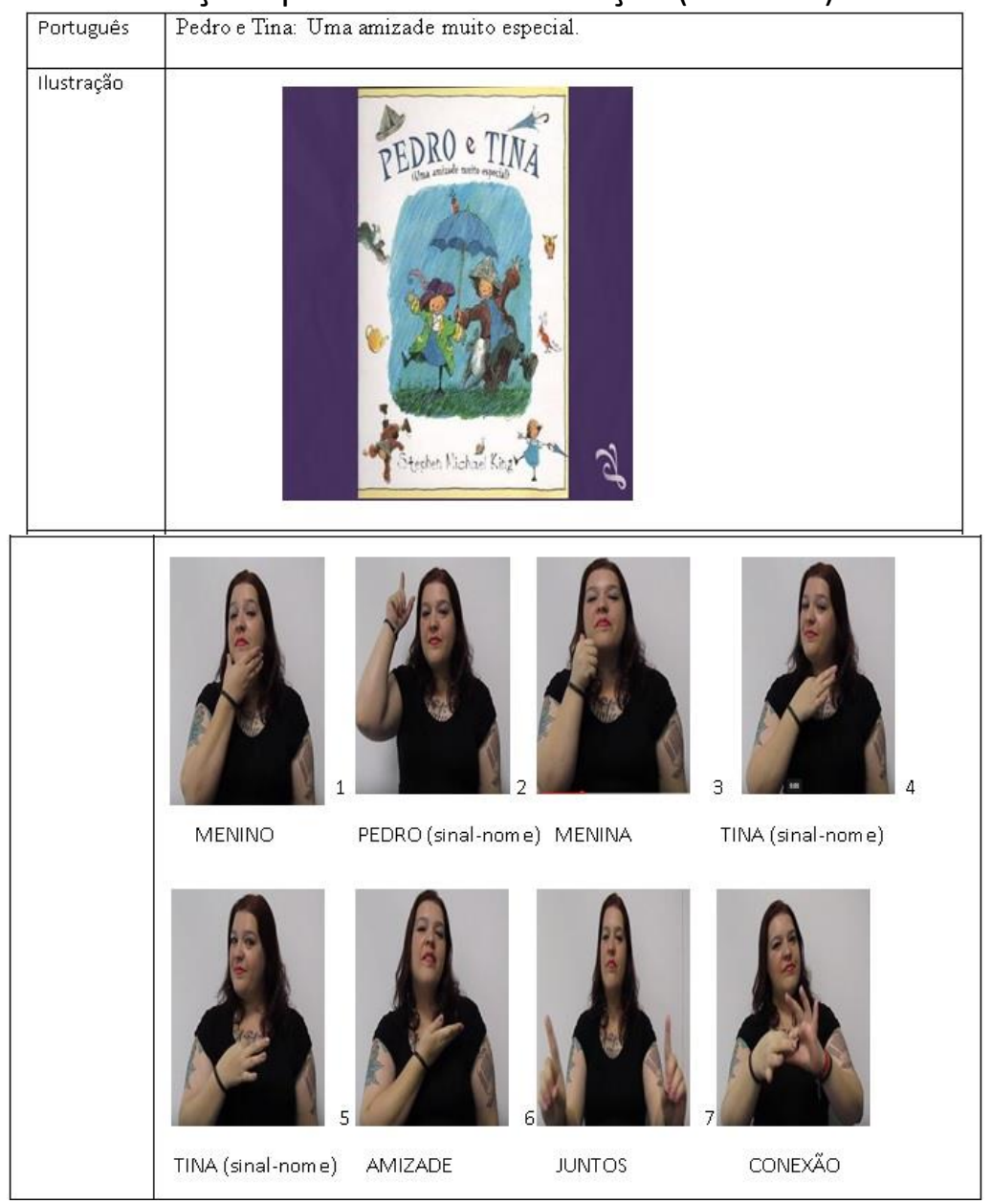

Fonte: Elaborada pelas autoras a partir do print screen das páginas do CD-ROM. 
Tabela 2. Sequência da sinalização apresentada na tradução (trecho 2)

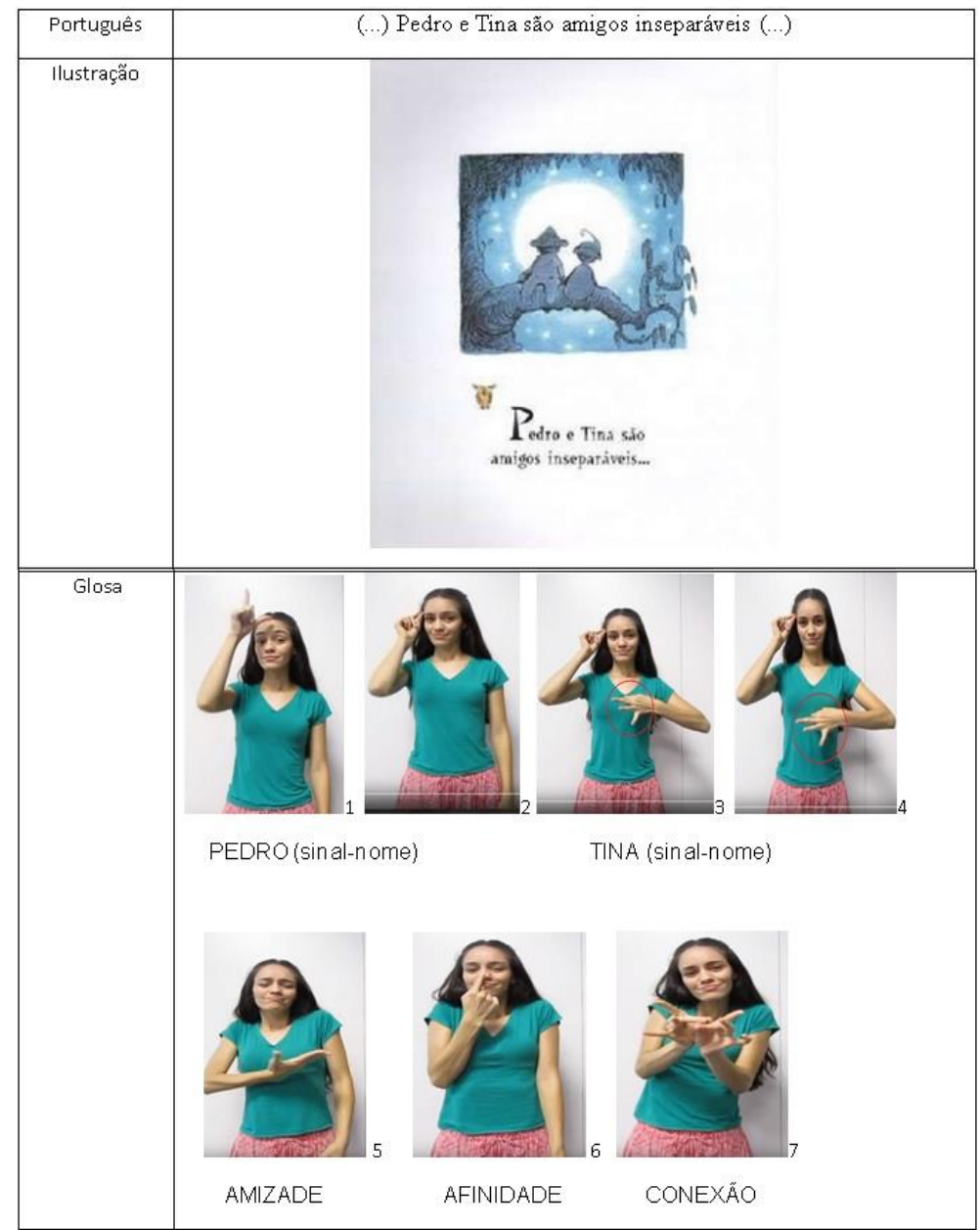

Fonte: Elaborada pelas autoras a partir do print screen das páginas do CD-ROM.

O trecho acima foi escolhido por conter os dois personagens e ter usado sinais de Pedro e de Tina simultaneamente.

\section{DISCUSSÃO}

Nos frames 1 e 2, do trecho 2, se forma o sinal de Pedro e, nos frames 3 e 4, o sinal de Tina. Para o sinal de Pedro, a configuração de mão escolhida foi devido ao acessório que ele usa, o chapéu feito de jornal. Já a escolha de a configuração de mão para o sinal de Tina, se devido sua característica psicológica. Além disso, foram escolhidos sinais que pudessem ser feitos com uma única mão, facilitando tradução de trechos, como no caso desse trecho escolhido "Pedro e Tina são amigos inseparáveis". Aliás, esse trecho foi escolhido justamente por conter os dois personagens e os sinais de ambos.

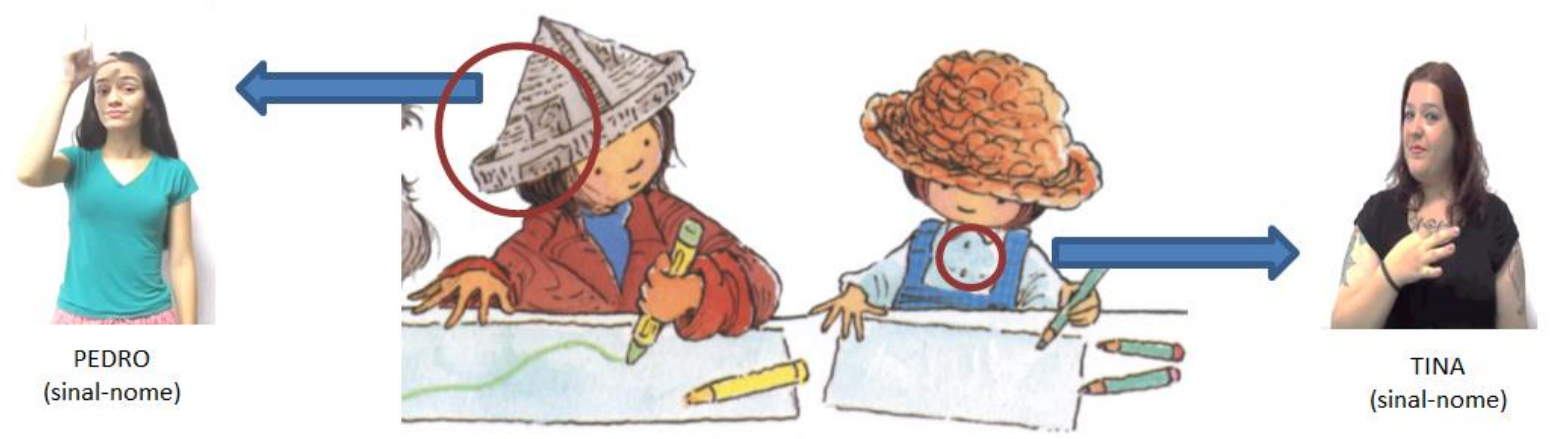

Figura 1. Esquema explicativo da motivação do sinal-nome dos personagens Fonte: Elaborada pela autora a partir do print screen das páginas do CD- ROM. 
Conforme esquema apresentado acima, a motivação para a criação do sinal-nome de Pedro está na ponta do seu chapéu de papel e a motivação para a criação do sinal-nome de Tina está nos botões de sua blusa. Para a produção dos dois sinais-nome utilizou-se da mesma configuração de mão final criando um efeito estético interessante e a possibilidade associação da personagem com a ilustração do livro.

Sobre a tradução dos nomes, Aguilera (2008) faz uma ótima observação sobre isso e diz que "um nome significativo tem um papel na história e não traduzi-lo é suprimir parte da função para qual o mesmo foi criado" (SILVA, 2009, p. 36). Peter Newmark (1982) diz "quando a denotação do nome não é conhecida ou é obscura para o leitor, o tradutor geralmente adiciona o nome genérico apropriado" (Peter Newmark, 1982, p. 12 apud Silva, 2009, p. 38).

Como salientamos acima, a necessidade da escolha do sinal para o nome próprio faz parte da tradução e, no caso do público infantil surdo, se faz necessário. Para expressar o nome do personagem Pedro o grupo de tradutores optou por utilizar um sinal arbitrário. Abres (2012) indica pesquisas que mostram que a maioria dos sinais dados às pessoas são de caráter descritivo. Porém, no caso dessa narrativa, as características físicas dos personagens são tão marcantes quanto suas personalidades, que inclusive, é o que envolve todo o contexto da estória.

Desta forma é possível observar o que o sinal de Pedro carrega uma característica concreta e descritiva, relacionada ao acessório que ele usa, o seu chapéu. O acessório o acompanha por toda a estória e representa características de sua personalidade, este é um acessório não "padronizado" e sim, improvisado, uma vez que é feito de jornal.

Silva (2009) salienta que quando os nomes não têm significado específico dentro da estória, como por exemplo, "Sra. Feliz", é possível mantê-lo. No caso do discurso apresentado no livro, apesar de Pedro ser um nome comum e não carregar nenhum significado para estória, na língua de sinais é preciso dar sinal aos personagens. Desta forma, a tradução foi na vertente de criar um sinal que pudesse fazer algum sentido, mesmo que abstrato. Sobre isso, Lacerda afirma:

[...] o tradutor-intérprete atua na fronteira entre os sentidos da língua de origem e da língua alvo, com os processos de interpretação relacionandose com o contexto no qual o signo é formado. O sentido do enunciado é construído na interação verbal, e é atualizado no contato com outros sentidos, na relação estabelecida entre interlocutores. A interpretação é um processo ativo, que procede de sentidos que se encontram, existindo, apenas, na relação entre sentidos, como um elo numa cadeia de sentidos. Pode-se dizer assim que a interpretação se revela na multiplicidade de sentidos existentes (LACERDA, 2000, p. 6 apud ALBRES, 2012, p.2).

Para tanto, justifica-se a escolha do sinal-nome por meio da afirmação de Bachktin e Volochinov em que afirmam que "há interação dinâmica dessas duas dimensões, o discurso a transmitir e aquele que serve para transmiti-Io" (BAKHTIN/VOLOCHINOV, 1992, p. 148 apud Albres, 2012, p.2) Desta forma, o tradutor possui liberdade para criar sua tradução para que faça sentido na língua alvo.

Sobre o processo de tradução da personagem Tina, a escolha foi permeada pelo aspecto de sua vestimenta e de característica psicológica da personagem. Os tradutores acreditavam que faria mais sentido explorar as características de sua personalidade ao invés das físicas. A personagem faz tudo de maneira perfeccionista, sendo o oposto do personagem Pedro. Por esse viés, optou-se por criar um sinal a partir da configuração de mão que dá origem morfologicamente ao sinal de "perfeito".

Para o sinal de Tina utilizou-se a configuração de mão (do sinal perfeito) para referir sua singularidade de ser. Além disso, aproveita sua característica física, sua blusa com botões, para apoio do sinal escolhido, a fim de legitimar a afirmação de sua característica como perfeccionista. 
A tradução se deu coletivamente, o processo de escolha passou por várias outras possibilidades, dentre elas, características de humor e ânimo, de caráter e personalidade dos personagens, de objetos sempre presentes, como por exemplo, o guarda-chuva de Tina, e também de outros aspectos físicos visualmente marcantes.

Finalmente, optou-se pelo traço acentuado dos vestuários dos personagens, um dos implicantes para tal decisão foi o número de mãos utilizadas para fazer o sinal, no caso apenas uma, pensando em descomplicar o processo de tradução do restante do texto.

Desta forma, a maior dificuldade nesta tradução de nomes foi conciliar um sentido para os leitores que tivesse relação com sua cultura e, facilitar a tradução utilizando apenas uma mão para os sinais próprios. Portanto, encontrou-se como solução usar de apoio ao sinal escolhido, as vestimentas, e como sentido os fatores psicológicos dos personagens, sem descontextualizar da narrativa e comtemplando os aspectos da língua de sinais.

Considerando o fato de que os surdos utilizam uma língua composta por sinais, que poderíamos grosseiramente comparar às palavras de uma língua oral, viu-se a necessidade de abrir mão do empréstimo linguístico da língua portuguesa, conhecido como alfabeto manual. De acordo com as ideias de Mourão (2012), “a Literatura Surda traz histórias de comunidades surdas. Essas histórias não interessam só para elas, mas também para as comunidades ouvintes, através da participação tanto de sujeitos ouvintes quanto de sujeitos surdos" (MOURÃO, 2012, p. 3). Dentre as características da literatura surda está a descrição detalhada dos personagens e a sua apresentação com um sinal-nome.

Optou-se pela utilização de sinal e não da datilologia do nome, visto que é forte e marcante tal utilização na comunidade surda, havendo um batismo com um sinal visual de todos que participam dela. Outro ponto importante levantado e considerado para a escolha do sinal que traduziria os nomes dos personagens foi o público alvo, a faixa etária para qual o livro é destinado, colaborando para a compreensão do leitor.

\section{CONCLUSÃO}

Deste modo, pudemos observar que as escolhas dos sinais para nomes próprios das personagens se deu pela vertente descritiva, por vezes de aspectos das vestimentas associadas a aspectos psicológicos. Desta forma, as imagens ilustradas influenciaram nas escolhas dos sinais, pois podiam representar traços dos sinais escolhidos. Como Albres (2012) reforça, as escolhas tradutórias também são ideológicas e subjetivas, ou seja, esta terá variação de acordo com fatores como a interpretação e entendimento do intérprete/tradutor e influências do contexto, como no exemplo deste trabalho, os fatores físicos e psicológicos dos personagens.

\section{REFERÊNCIAS}

ALBRES, Neiva de Aquino. A construção de sinais-nome para personagens na tradução de literatura infanto-juvenil para libras. Belas Infiéis, Brasília, v. 5, n. 1, p. 73-92, fev-jun. 2016. Disponível em: <http://periodicos.unb.br/index.php/belasinfieis/article/view/19508> Acesso em 04.08.2016.

Tradução de literatura infantil: entre a construção de sentidos e o uso dos recursos linguísticos. In: III Congresso Brasileiro de Pesquisas em Tradução e Interpretação de Língua Brasileira de Sinais e Língua Portuguesa, 3, 2012,. Florianópolis-SC. Anais, UFSC: 2012.

AGUILERA, Elvira Cámara. The translation of Proper Names in Children's Literature. Disponível em: <http://ler.letras.up.pt/uploads/ficheiros/4666.pdf>. Acesso em 10 de agosto 2016.

BAKHTIN, M. (Volochinov). Marxismo e Filosofia da Linguagem. (Trad.) 6a ed. São Paulo: Ed. Hucitec, 1992. (texto original de 1929). 
KARNOPP, Lodenir Becker. Produções culturais de surdos: análise da literatura surda. Cadernos de Educação | FaE/PPGE/UFPel | Pelotas [36]: 155 - 174, maio/agosto 2010.

LACERDA, C. B. F. A prática pedagógica mediada (também) pela língua de sinais: trabalhando com sujeitos surdos. Cad. CEDES [online]. 2000, v. 20, n. 50, pp. 70-83. https://doi.org/10.1590/S0101-32622000000100006

LIDDELL, S. K. Grammar, gesture, and meaning in American Sign Language. 1.ed. Cambridge: Cambridge University Press. 2003. https://doi.org/10.1017/CBO9780511615054

MOREIRA, Renata Lucia. Uma descrição de Dêixis de Pessoa na língua de sinais brasileira: pronomes pessoais e verbos indicadores. Dissertação de mestrado em Linguística. Faculdade de Filosofia, Letras e Ciências Humanas (FFLCH)- USP, 2007.

MOURÃO, Claudio Henrique Nunes. Adaptação e tradução em literatura surda: a produção cultural surda em língua de sinais. In: IX ANPED Sul. Seminário de Pesquisa em Educação da Região Sul. 2012

NEWMARK, Peter. Approaches to translation. Oxford, Pergamon, 1982.

SILVA, Clara Peron da. A literatura infantil em tradução: especificidades da tradução de livros da série Mr. Men e Little Miss, de Roger Hargreaves, para o português do Brasil. 2009. $65 \mathrm{f}$. Monografia (Bacharelado em Letras: Ênfase em Tradução-Inglês) - Faculdade de Letras, Universidade Federal de Juiz de Fora, Juiz de Fora, 2009.

SILVEIRA, Carolina Hessel. O currículo de Língua de Sinais na Educação de surdos. Dissertação de Mestrado em Educação - Universidade Federal de Santa Catarina, 2006.

SOBRAL, Adail Ubirajara. A concepção de autor do Círculo Bakhtin, Medvedev, Voloshinov: confrontos e definições. Macabéa: Revista Eletrônica do Netlli, Crato 1.2 (2012): 123-142.

STROBEL, Karin. As imagens do outro sobre a Cultura Surda. Florianópolis: Ed. da UFSC, 2008.

SUTTON-SPENCE, Rachel; QUADROS, Ronice Müller. Poesia em língua de sinais: traços da identidade surda. In: QUADROS, Ronice Müller (org.). Estudos Surdos I. Petrópolis, RJ: Arara Azul, 2006.

WILCOX, S.; WILCOX, P. Aprender a ver. Tradução por Tarcísio Leite. Rio de Janeiro: Arara Azul, 2005. 